\title{
La decisión de morir, ¿libertad o derecho? Una perspectiva desde el ámbito español
}

\author{
The Decision to Die, Freedom or Right? A Perspective from the Spanish \\ Ambit
}

María del Pilar Molero Martín-SALAS 1

Resumen: Posiblemente, una de las decisiones más difíciles a las que tenga que enfrentarse el ser humano sea la de poner fin a su propia vida. En el presente trabajo se trata de analizar el carácter jurídico de la misma, y si dicha decisión puede entenderse como una libertad o como un derecho. La consideración en uno y otro sentido determinará las facultades que tiene el titular del derecho a la vida, y las consecuencias que dicha decisión podría tener para terceros.

Palabras clave: Decisión, Eutanasia, Libertad, Derecho

\begin{abstract}
Possibly one of the most difficult decisions that humans have to face is to end their own life. The present work tries to analyze its legal nature, and if said decision can be understood as a freedom or as a right. Consideration in both directions will determine the powers that the holder of the right to life has, and the consequences that said decision could have for third parties.
\end{abstract}

Keywords: Decision, Euthanasia, Freedom, Right

\section{Introducción}

Una de las pocas cosas que podemos afirmar con rotundidad es que todos moriremos. No suele gustarnos hablar de la muerte, y normalmente deseamos que llegue lo más tarde posible.

\footnotetext{
${ }^{1}$ Universidad de Castilla-La Mancha. Dra. en Derecho. Profesora de Derecho Constitucional. Cuenca. España. Correo electrónico: mariapilar.molero@uclm.es
}

Fecha de recepción: 2021-01-25; fecha de aprobación: 2021-04-27 
Sin embargo, hay veces, que el titular del derecho a la vida toma la decisión de no seguir viviendo. Las razones pueden ser diversas, y el suicidio no siempre es una posibilidad para aquel que quiere morir, es por ello que algunos estados permiten que se pueda ayudar a la persona que no quiere seguir viendo; bien mediante la asistencia al suicidio o con la práctica de la eutanasia.

Cabe puntualizar desde el inicio, que si bien la palabra eutanasia es posiblemente de las más usadas y conocidas, no todos los supuestos se agotan con la misma. Aunque de manera sucinta, es importante distinguir entre diferentes conceptos 2 :

-La cooperación o asistencia al suicidio: nos encontramos dentro del ámbito del suicidio, sobre todo en cuanto a que es la propia persona la que pone fin a su vida, aunque con una diferencia muy importante, que necesita la ayuda de un tercero para llevar a cabo su decisión de morir. Sin la participación de ese tercero, la persona no podría terminar por ella misma con su vida.

-Eutanasia: en la doctrina encontramos numerosas definiciones al respecto. Atendiendo a los elementos de mayor acogida entre la doctrina, podemos entender por eutanasia el provocar la muerte, por acción o por omisión, de aquella persona que sufre una enfermedad incurable, por requerimiento de esa persona y con la finalidad de evitarle un sufrimiento continuo e insoportable.

Se suele distinguir entre eutanasia activa, cuando la muerte se lleva a cabo mediante una acción, y eutanasia pasiva, cuando la muerte se realiza por omisión.

Además de la activa y la pasiva, quizá la más referida entre la doctrina sea la eutanasia activa indirecta, entendida en términos generales como la administración de determinados fármacos para paliar el dolor; aunque suele llevar aparejada la consecuencia de acortar la vida.

Son diversos los estados que han legalizado este tipo de actuaciones, en unos casos mediante la asistencia al suicidio, en otros casos a través de la eutanasia. Las regulaciones más avanzadas en la materia las encontramos en Países Bajos y Bélgica. El estado pionero fue Países Bajos,

${ }^{2}$ Para un análisis más profundo puede consultarse Molero (2014), pp. 195 y ss. 
aprobando una ley que despenaliza ciertos supuestos ${ }^{3}$. Siguiendo este modelo, poco después, Bélgica $^{4}$ también despenalizan determinados supuestos de eutanasia 5 .

La normativa más reciente la encontramos en España, a través de Ley Orgánica 3/2021, de 24 de marzo, de regulación de la eutanasia ${ }^{6}$. Prevé la posibilidad de practicar la eutanasia en determinados supuestos.

Sin duda debe ser una decisión muy dura: la de no querer seguir viviendo. Normalmente, se suele hablar de decisión libre, voluntaria, reiterada, inequívoca..., pero ¿qué carácter tiene dicha decisión? Es una libertad, que me otorga un ámbito dentro del cual puedo decidir qué hacer o que no hacer, o es un derecho, que puedo oponer a los terceros, e incluso exigir su ayuda si por mi mismo no puedo llevar a término la decisión adoptada. ¿Qué cabe esperar del tercero ante mi decisión de no seguir viviendo?

Por tanto, el objetivo principal de este trabajo será determinar si la decisión de morir es una libertad o un derecho, y qué facultades otorgaría al titular del derecho a la vida una y otra consideración.

Dada la reciente regulación española al respecto, el análisis se circunscribe casi por completo a este ordenamiento jurídico, si bien también encontramos alusiones al ámbito comparado. Las

${ }^{3}$ Ley de terminación de la vida a petición propia y del auxilio al suicidio.

${ }^{4}$ Ley relativa a la eutanasia.

${ }^{5}$ Algunas otras regulaciones son las siguientes: Australia. Aunque su duración fue efímera, ya que se derogó a los 9 meses, la primera regulación sobre eutanasia se produce en uno de sus territorios autónomos, concretamente el Territorio Norte, aprobó el 1 de julio de 1996 una ley que despenalizaba ciertos supuestos de eutanasia. Se trataba de la Ley de Derechos de los enfermos terminales. De manera mucho más reciente se ha aprobado en el estado de Victoria la ley de muerte asistida, que entró en vigor en junio de 2019. Western aprobó la suya en diciembre de 2019 y entrará en vigor en 2021. Nueva Zelanda, por su parte, aprobó en referénd um de octubre de 2020 una ley de eutanasia que entrará en vigor en noviembre de 2021. Suiza: El Código Penal suizo tipifica como delito tanto la eutanasia activa como la inducción o la cooperación al suicidio, si existe un interés propio en quien induce o coopera, sin embargo, no se dice nada del auxilio al suicidio cuando no existe tal interés, lo que se ha interpretado como la no sanción al que auxilia al suicidio por motivos altruistas. Oregón: El 8 de noviembre de 1994 se aprueba por referéndum una ley que permite el suicidio asistido. Aunque se trata de una regulación similar a la europea, pretende ser un sistema más garantista, pues ademá s de que solo prevé el suicidio asistido, y no la eutanasia, también prevé una serie de condiciones que le hacen ser más estricto en su aplicación. De manera posterior otros muchos estados en EE.UU. Colombia: El Código Penal colombiano tipifica como delito tanto la eutanasia activa como la cooperación al suicidio, como formas atenuadas del homicidio, sin embargo, la Corte Constitucional colombiana, dicta el 20 de mayo de 1997 la sentencia № 239/97. Se trata de una sentencia sorprendente en la que se concluye que la conducta del médico que "por piedad" colabore con el enfermo terminal para que ponga fin a su existencia no será punible, provocando una contradicción entre el Código Penal y la interpretación constitucional dada por la Corte. Uruguay: El Código Penal uruguayo faculta a los jueces para eximir de la pena al que mata a una persona que así lo pide, por motivos piadosos. Aunque se trata de una acción considerada homicidio, el hecho de tratarse de un homicidio piadoso se entiende como causa de impunidad, si bien se exige que el autor que lleva a cabo la actuación carezca de antecedentes penales (no se dice nada de que deba ser un médico) y la petición de la persona que desea morir debe ser reiterada. Alemania: Su Código Penal no castigaba el suicidio ni la participación en el mismo por parte de un tercero, sin embargo, sí castigaba lo que denomina "homicidio a petición" y que se podría equiparar a la eutanasia activa. Ante esta regulación, parte de la doctrina consideraba que tanto el suicidio como la participación en el mismo era impune, pues no se castigaba a quien prepara una bebida con una cantidad de veneno suficiente para matar a una persona, cuando es la propia persona la que finalmente y de manera autónoma bebe el preparado, pero sí se castigaba al tercero, si es él mismo el que administra la sustancia. En 2015 se reforma la norma para castigar expresamente el suicidio asistido, si bien con la reciente sentencia de 26 de febrero de 2020, el Tribunal Constitucional reconoce el derecho a la autodeterminación al final de la vida; anulando el artículo del Código Penal que prohibía dicha práctica.

${ }^{6}$ Entrará en vigor el 25 de junio de 2021. 
mismas se refieren a Alemania y a Italia, referentes siempre importantes para el ordenamiento español.

\section{Prohibiciones, obligaciones y permisos, y su conexión con la libertad}

La disposición de la propia vida, y las decisiones que puede adoptar el ser humano con respecto a la terminación de la misma, han sido tratadas por la doctrina desde diversos enfoques tales como el jurídico, el ético, el sociológico, el médico e incluso el religioso. Si centramos la atención en el ámbito jurídico, entiendo que previamente resulta indispensable el acercamiento a una serie de conceptos relacionados con la Teoría y Filosofía del Derecho.

Si tratamos de contestar a la pregunta ¿podemos (o no) disponer de la propia vida?, lo primero que debemos analizar es si existe algún tipo de norma que me obligue, permita o prohíba algo al respecto, o simplemente si existe una omisión por parte del ordenamiento jurídico.

No es habitual encontrarnos con normas que explícitamente prohíban. Es curioso observar como prácticamente no existen prohibiciones expresas, sino que más bien se establecen sanciones o castigos para determinados supuestos; lo que nos indica que están prohibidos.

Con las obligaciones ocurre algo similar, sobre todo si tenemos en cuenta que en definitiva una prohibición es la obligación de no hacer. Por ejemplo, ni la Constitución española (en adelante CE) ni la ley dicen de manera expresa que esté prohibido ayudar a morir a un tercero, ni que exista la obligación de no ayudar a morir a un tercero, sin embargo, el Código Penal español, sí tipifica dicha actuación, por lo que debemos entender que está prohibida7.

Por otra parte, el principio jurídico que dice "que todo lo que no está prohibido está permitido", nos indica que además de normas de prohibición y obligación, también existen permisos, que

\footnotetext{
${ }^{7}$ El art. 143 del Código Penal español, sin contener ninguna prohibición expresa, tipifica como delito la inducción al suicidio, la cooperación en el mismo, tanto si con dicha cooperación se llega a ejecutar o no la muerte de la persona, y causar o cooperar en la muerte de una persona dentro de lo que podría llamarse un contexto eutanásico (existencia de una enfermedad grave e incurable, que provoca sufrimientos insoportables). Esta tipificación nos indica que dichas conductas no pueden realizarse. Al margen de lo que en este punto se trata de exponer, cabe matizar que, tras la aprobación de la ley de la eutanasia, a la que me refería antes, el art.143 sigue plenamente vigente, si bien se ha incorporado un apartado nuevo que indica lo siguiente: "5. No obstante lo dispuesto en el apartado anterior, no incurrirá en responsabilidad penal quien causare o cooperare activamente en la muerte de otra per sona cumpliendo lo establecido en la ley orgánica reguladora de la eutanasia".
} 
nos autorizan o facultan, nos permiten un hacer o un no hacer, en definitiva, nos otorgan una libertad 8 .

Sin embargo, cuando nos encontramos ante el principio "todo lo que no está prohibido está permitido" debemos entender que se trata de un permiso en sentido débil ${ }^{9}$. Pretendemos hacer una acción o una omisión, y puesto que no hay ninguna norma que lo prohíba, entendemos que la conducta está permitida. Sin embargo, también podemos encontrarnos con permisos en sentido fuerte, es decir, aquellos permisos recogidos expresamente por una norma. Si afirmamos que algo tiene la característica de permitido es porque existe una norma en el ordenamiento jurídico que así lo dice, o porque el ordenamiento simplemente no se ha referido a ese hecho ni para mandarlo ni para prohibirlo, lo cual nos hace pensar que está permitido.

Son numerosos los autores que defienden la conexión existente entre el concepto de libertad jurídica y el concepto de permiso, es el caso de Hobbes o Benthan que vienen a decir que en aquellos casos en los que no se dice nada de un hecho, ni para prohibirlo ni para mandarlo, será cada persona la que elija libremente ${ }^{10}$, o Alexy que dice que la negación de una prohibición da lugar a un permiso de hacer o permisión positiva, y la negación de un mandato da lugar a un permiso de no hacer o permisión negativa. La combinación de la positiva y la negativa da lugar a lo que denomina posición libre, cuya importancia en el análisis de la libertad considera esencial ${ }^{11}$.

Si retomo la idea de la distinción entre el permiso sometido a norma y el permiso no sometido a norma, y considero que los conceptos de libertad y de permisión están conectados, el permiso previsto en la norma y el no previsto darán lugar a libertades que han de ser distintas. Cuando no existe ninguna norma que prevea ese permiso dará lugar a lo que podríamos denominar mera libertad, sin embargo, cuando el permiso sí está previsto por una norma, o se deduce de ella, podríamos hablar de libertad regulada. Veamos estos conceptos con más detalle.

\footnotetext{
${ }^{8}$ Cuando hablo de libertad me refiero en todo momento al concepto jurídico de la misma. Berlin, cuando se refiere al término libertad, dice "...que se trata de un término con un significado tan poroso que parece que no hay interpretación que lo resista..." Berlin (2005), p. 47.

${ }^{9}$ Von Wright, quien asienta toda la lógica deóntica que hoy conocemos, realizó la distinción entre permiso en sentido fuerte y permiso en sentido débil. Habla de permiso en sentido fuerte cuando ese acto ha sido sometido a norma y se decide permitirlo expresamente (o es consecuencia lógica de otras normas ya emitidas). El permiso en sentido débil es aquel que no se ha sometido a norma, es decir, el acto se entiende permitido pues no ha sido prohibido, Von Wright (1979), pp. 100 y ss.

${ }^{10} \mathrm{Ambas}$ referencias las he tomado de Alexy (2017), pp. 218 y 219.

${ }^{11}$ Alexy (2017), pp. 200 y 201.
} 


\section{Mera libertad y libertad regulada}

Nos encontramos ante una mera libertad cuando el ordenamiento jurídico no ha regulado un determinado hecho, ya sea de acción o de omisión, ni para mandarlo ni para prohibirlo. Ante la ausencia de regulación entendemos que el hecho está permitido, es decir, tenemos libertad para hacerlo o no hacerlo. Entra en juego el principio jurídico mencionado de que todo lo que no está prohibido está permitido.

Denomino libertad regulada a aquella que se deriva de un permiso que ha sido sometido a norma o, como diría Von Wright, permiso en sentido fuerte, es decir, es el propio ordenamiento jurídico el que establece que ese hecho está permitido, siendo el destinatario de la norma el que decide si hacerlo o no hacerlo.

El hecho de que algunas libertades no estén previstas por los ordenamientos jurídicos y otras sí lo estén expresamente, nos sugiere que alguna diferencia debe existir entre ellas. El ordenamiento jurídico no puede catalogar todas las acciones u omisiones posibles pues estas son infinitas. Cuando una acción u omisión está regulada por el Derecho nos indica que su importancia jurídica es mayor que la de aquel otro hecho que no se prevé. La finalidad de este reconocimiento no puede ser otra que otorgar a ese hecho una cierta protección; aumentar la seguridad jurídica. El hecho de que la libertad esté regulada por el Derecho impide que pueda ser limitada sin más. Aunque deban admitirse ciertas restricciones, estas deberán justificarse. Normalmente cuando se limita una libertad es porque entra en conflicto con otros intereses también dignos de protección. Precisamente, la consideración de estos otros intereses en juego es lo que justificaría la restricción.

Sin embargo, como veremos, la distinción aquí propuesta carece de valor práctico, conservando únicamente su valor teórico, si entendemos que en el ordenamiento jurídico existe una norma general de libertad, ya que la existencia de esta supone afirmar que, prima facie, todas las acciones u omisiones que realice el individuo están amparadas en esta norma; aunque posteriormente puedan existir restricciones o límites en el ejercicio de las mismas. Ya no es necesario preguntarse si el permiso del que deriva la libertad está o no previsto por el ordenamiento jurídico, pues en hipótesis todas nuestras decisiones están cubiertas por esa norma general de libertad, y por tanto previstas, o lo que es lo mismo, si afirmamos que existe una norma general de libertad, todas las libertades son libertades reguladas. Veámoslo con algo más de detalle. 


\section{La norma general de libertad}

Quizá uno de los lugares en que más claramente se ha reconocido la existencia de esta norma sea en Alemania. El Tribunal Constitucional Federal interpretó el libre desarrollo de la personalidad (previsto en el art. 2 de la Ley Fundamental) como derecho general de libertad 12 . El Tribunal considera que se trata de un derecho fundamental independiente que garantiza la libertad general de la acción humana. Este derecho abarca el poder hacer o no hacer lo que se quiera y un derecho a no impedimento (siempre que no existan restricciones) ${ }^{13}$.

En cuanto al ordenamiento jurídico italiano, parte de la doctrina también considera que en la Constitución italiana existen argumentos suficientes que permiten afirmar la existencia de una norma general de libertad, es el caso de Rodotà pues considera que en la Constitución italiana hay bastantes argumentos jurídicos para entender que cada cual puede dirigir su vida como quiera, la libertad personal prevista en el art.13, el reconocimiento de una existencia libre y digna en el art. 36, respeto a la persona humana en el art. 32 y la no discriminación prevista en el art. $3^{14}$. En un sentido similar, y refiriéndose de manera más concreta a las decisiones que afectan al propio cuerpo, Romboli afirma que la libertad de decisión en cuanto a los actos que inciden en el propio cuerpo puede ser considerada como valor constitucionalmente tutelado, cuyo fundamento se encontraría principalmente en los arts. 13 y 32 de la Constitución italiana15.

En lo que respecta al ordenamiento jurídico español, y para abordar este tema correctamente, considero que deben responderse principalmente dos cuestiones. Comencemos por la primera, ¿existe en el ordenamiento español una norma general de libertad? Dar una respuesta afirmativa o negativa supone partir de dos posiciones jurídicas totalmente distintas. Como bien expone Prieto Sanchís, “...las libertades pueden concebirse como la regla básica del sistema, limitada aquí o allá por concretas prohibiciones o mandatos, cuya existencia ha de justificarse; o bien, a la inversa, puede interpretarse que el poder político goza de legitimidad para establecer normas imperativas con el único límite del respeto por los concretos derechos fundamentales..." 16 . Gascón Abellán considera que lo general es la libertad y que las prohibiciones y mandatos son

\footnotetext{
${ }^{12}$ El 16 de enero de 1957 (caso Elfes) es una de las primeras sentencias del Tribunal Constitucional Federal alemán, aunque sentencias posteriores confirman el contenido de este primer pronunciamiento.

${ }^{13}$ Una explicación más detallada de jurisprudencia y doctrina en cuanto a cláusulas generales, tanto en Alemania como en Italia y EE. UU. la encontramos en Díaz (2018), pp. 457 y ss. También se puede consultar, para el caso concreto del derecho general de libertad en Alemania, a Alexy (2017), pp. 299 y ss.

${ }^{14}$ Rodotà (2008).

${ }^{15}$ Romboli (1994), p. 239.

${ }^{16}$ Prieto (1990), p. 158
} 
límites a la libertad, no concibe que las libertades sean la excepción a una regla general de obligación 17 .

Personalmente, entiendo que debe partirse de la primera de las concepciones, pues una afirmación como la segunda supone reconocer al legislador un poder prácticamente ilimitado cuya única barrera sería el respeto por los derechos fundamentales concretos.

Por tanto, si partimos de la primera de ellas, afirmamos que la regla general es el reconocimiento de una norma general de libertad, y que las prohibiciones o mandatos que pueden limitar ese espacio, no solo son la excepción, sino que deben justificarse, como dice Gascón Abellán, aunque ella se refiere al caso concreto de la objeción de conciencia, si bien puede aplicarse aquí perfectamente, “...la existencia de un derecho general no supone que deba tolerarse la violación de cualquier deber jurídico, sino solo una presunción de que la persona que incumple su obligación por motivos de conciencia se halla protegida por un principiogeneral del ordenamiento"18.

Prieto Sanchís considera que sí existe una norma general de libertad en el ordenamiento español, a la que considera norma de clausura del sistema de libertades. Son varios los argumentos que este autor utiliza para afirmar la existencia de esta norma, el más importante el reconocimiento, en el art. 1.1 de la CE, de la libertad como valor superior del ordenamiento jurídico, aunque también se refiere a los derechos inviolables y al libre desarrollo de la personalidad, reconocidos en el art. 10.1. Sin embargo, este autor va más allá, pues encuentra fundamento para esta norma en un derecho constitucional en sentido estricto, concretamente en el art. 16.1, que reconoce la libertad ideológica, religiosa y de culto, considerando que incluye implícitamente la libertad de conciencia, entendida esta como “...una libertad eminentemente práctica que consiste no solo en pensar y creer sin ataduras jurídicas, sino sobre todo en actuar de forma coherente con las propias convicciones"19. Con respecto a los límites a esa norma, entiende que toda restricción debe justificarse en la propia Constitución, “...basta, a mi juicio, con que el fin perseguido no sea contrario a la Constitución y represente un sacrificio razonable para el derecho" 20 . Para este autor, como para otros muchos, el conflicto que se produce entre el

\footnotetext{
${ }^{17}$ Gascón (1999), p. 280. De manera similar en Gascón (2010), p. 149.

${ }^{18}$ Gascón (1999), p. 255.

${ }^{19}$ Prieto (1990), pp. 160 y ss.

${ }^{20}$ Prieto (2000), pp. 434 y ss.
} 
principio que resulta afectado por la ley restrictiva y el que sirve como justificación a la misma, ha de resolverse mediante la ponderación ${ }^{21}$.

Díaz Revorio, por su parte, también considera que “...existen fundamentos más que suficientes para entender que la CE contiene una norma general de libertad..."22. Este autor utiliza como principales argumentos la mención que se hace en el art. 10.1 a los derechos inviolables y al libre desarrollo de la personalidad, el reconocimiento de la libertad como valor superior y el mandato que establece el art. 9.2 para los poderes públicos que deberán promover las condiciones para que la libertad sea real y efectiva. Asimismo, fundamenta su existencia en otros derechos, como los previstos en el art. 16, aunque de una forma muy distinta a como lo hace el autor anterior, pues entiende que este precepto deberá ser interpretado en sentido amplio $^{23}$. También en un sentido similar al anterior autor, y con respecto a las limitaciones a esta norma general de libertad, considera que estas deben tener su fundamento en la propia CE, bien de forma directa o de forma indirecta, siendo la ponderación el mecanismo adecuado para determinar si prevalece el principio general de libertad o la limitación ${ }^{24}$.

Con respecto a la jurisprudencia, he de decir que la existencia de una norma general de libertad en el ordenamiento jurídico español, ha sido reconocida tanto por el Tribunal Constitucional español (en adelante TC) como por el Tribunal Supremo español (en adelante TS).

En cuanto al TC, son diversas las sentencias que aluden de una u otra forma a esta norma, a la que el Alto Tribunal se refiere como principio; “...ante el principio general de libertad que inspira nuestro sistema constitucional..." 25 “...el principio general de libertad que la Constitución consagra..."26, derivando la existencia de este principio del art. 1.1. de la CE, donde se reconoce la libertad como valor superior del ordenamiento jurídico.

En lo que respecta al TS también reconoce, o más bien da por hecho, la existencia de un principio general de libertad que derivaría de los arts. 1.1 y 9.2 de la CE, "visto el principio general de libertad que consagran los artículos 1.1 (valor superior de la libertad) y 9.2 (promoción de la libertad) de la Constitución Española..."27.

\footnotetext{
${ }^{21}$ Prieto (2000), pp. 442 y ss.

${ }^{22}$ Díaz (2000), p. 248 y Díaz (2009), pp. 94 y 95.

${ }^{23}$ Díaz (2000), pp. 248 y 249.

${ }^{24}$ Díaz (2000), p. 258.

${ }^{25}$ STC 139/1989, de 20 de julio, f.j. 2, reiterando ideas anteriores de las SSTC 89/1989, de 11 de mayo y 67/1985, de 24 de mayo.

${ }^{26}$ STC 83/1984, de 24 de julio, f.j. 3.

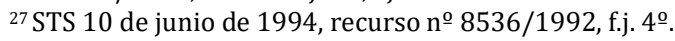


Personalmente, considero que en la CE hay fundamentos suficientes para entender que existe una norma general de libertad, que en principio daría cobertura a cualquier acción u omisión, aunque pueden existir limitaciones o restricciones que afecten a esa norma de libertad. Sin duda el principal fundamento para afirmar la existencia de este espacio es el reconocimiento, ya en el art. 1 de la CE, de la libertad como valor superior del ordenamiento jurídico, valor que tiene su más clara manifestación en el libre desarrollo de la personalidad reconocido en el art. 10.1. Esto no significa que no tenga manifestaciones en otros preceptos, es decir, también otros derechos o libertades reconocidos expresamente en la CE pueden servir como fundamento para afirmar la existencia de una norma general de libertad, pero no todos ellos servirán como argumento para reconocer la existencia de todas las manifestaciones de la libertad.

Contestada la primera de las preguntas, debemos dar respuesta a la segunda, ¿qué tipo de norma es?

Se trata de una cuestión de suma importancia, pues no es lo mismo admitir que se trata de un derecho subjetivo, que considerar que nos encontramos ante un derecho fundamental previsto como tal, de manera expresa, por el texto constitucional 28 .

En cuanto a la doctrina, Díaz Revorio se refiere a las manifestaciones del valor superior libertad, libre desarrollo de la personalidad y los derechos inherentes (ya vimos que estos son los fundamentos que utiliza el autor para hablar de la norma general de libertad) y considera que aquellas que derivan de derechos fundamentales son las únicas que gozarán de las máximas garantías, pudiendo configurarse el resto como derechos subjetivos ${ }^{29}$. Prieto Sanchís entiende que, de las ilimitadas posibilidades de la conducta humana, solo algunas están tipificadas por los derechos previstos en la CE y cuyas limitaciones ya vimos que considera deben estar justificadas, y acudir a la ponderación cuando sea necesario. Sin embargo, existen otras actuaciones que no están previstas en ningún derecho, pero no por ello carecen de tutela “...toda norma que imponga mandatos o prohibiciones, limitando así la libertad natural, ha de ser concebida y tratada como una norma que limita derechos fundamentales”30 “...todo lo que la Constitución no prohíbe u ordena debe reputarse en principio jurídicamente permitido, y la extensión a esa esfera de inicial

\footnotetext{
${ }^{28}$ Son numerosísimas las obras escritas hasta el momento en las que se analizan, de una u otra forma, los derechos fundamentales, por lo que resulta prácticamente imposible referirme a todas ellas. En lo que respecta a los antecedentes históricos del concepto "derecho fundamental", por ejemplo, podemos consultar, Bastida y otros (2004), pp. 17 y ss. o en Pérez (2018), pp. 235 y ss. Algunas de las más interesantes en cuanto a teoría general de los derechos fundamentales, Ferrajoli (2013) y Alexy (2017). Un análisis más concreto de los derechos fundamentales en la CE podemos encontrarlo en Díez-Picazo (2013) y García (2013), entre otros.

${ }^{29}$ Díaz (2018), pp. 527 y 528.

${ }^{30}$ Prieto (2000), p. 464.
} 
permisión de normas imperativas que limitan la libertad requiere un respaldo constitucional suficiente..."31. De sus explicaciones deducimos que incluso aquellas manifestaciones que derivan de la libertad natural, son consideras por el autor como derechos subjetivos.

En lo que respecta al TC se refiere a la multitud de manifestaciones que pueden derivarse de la libertad "a secas", pero aclara que no todas estas manifestaciones van a formar parte de un derecho fundamental, aunque tengan mucha relación con él. Esto significa que limitar una determinada manifestación no siempre supone limitar un derecho fundamental, “...(l)os derechos fundamentales, que garantiza la libertad, no tienen ni pueden tener como contenido concreto cada una de las manifestaciones de su práctica, por importantes que estas sean en la vida del individuo..." 32 . Parece deducirse que el TC distingue dos tipos de manifestaciones, todas derivadas del principio general de libertad: aquellas que forman parte de un derecho fundamental y que gozan de máximas garantías, y aquellas que no se integran en un derecho fundamental, y que por tanto tienen una protección menor que las anteriores. Podemos decir que el TC, más que analizar la norma general de libertad en sentido abstracto y tratar de determinar qué tipo de norma es, lo que hace es estudiar cada una de las manifestaciones concretas de la libertad y determinar que aquellas que forman parte de un derecho fundamental gozan de las máximas garantías y comprenden tanto la dimensión objetiva como la dimensión subjetiva, pero aquellas manifestaciones que no forman parte de ningún derecho fundamental, no están protegidas por las garantías más excepcionales. Sin embargo, y aunque no gocen de estas garantías, ¿podemos afirmar que todas ellas comprenden una dimensión subjetiva? Ciertas sentencias ponen de relieve que el Alto Tribunal no concede esta consideración a todas las posibles manifestaciones. Por ejemplo, en lo que respecta al derecho a la vida, el TC considera que al no existir un derecho a la propia muerte, la decisión de un individuo de quitarse la vida, aun siendo una manifestación de la libertad, no se considera derecho subjetivo, ya que no podemos acudir a los poderes públicos para que impidan la obstaculización del ejercicio de esta manifestación por parte de un tercero ${ }^{33}$.

\footnotetext{
${ }^{31}$ Prieto (2000), p. 465.

${ }^{32}$ STC 89/1987, de 3 de junio, f.j. 2.

${ }^{33}$ La que se expone es la argumentación que existe del TC hasta el momento. Posiblemente, tras la entrada en vigor de la reciente ley de eutanasia, será recurrida y tendremos la oportunidad de conocer una interpretación constitucional más actual. Lo que el TC ha dicho hasta el momento es que el derecho a la vida no incluye el derecho a la muerte, así lo expuso en tres sentencias que se dictaron para el caso Grapo, principalmente en las dos primeras. SSTC 120/1990, de 27 de junio, 137/1990, de 19 de julio y 11/1991, de 17 de enero. Se trata de un famoso caso en el que un grupo de reclusos se ponen en huelga de hambre para conseguir un acercamiento a cárceles más próximas a sus residencias. Los reclusos quieren ejercer su libertad hasta el final, aunque ello les suponga la muerte. El TC considera que el derecho a la vida reconocido en el art.15 de la CE no incluye el derecho a la muert e. El titular del derecho tiene libertad para disponer de ella, pues el suicidio no está castigado, pero no puede configurarse como un derecho a la propia muerte. El Alto Tribunal considera que una de las manifestaciones de la libertad del individuo es disponer de su vida, pero esta facultad no puede concebirse como un derecho subjetivo que implique que los poderes públicos deban impedir
} 
Evidentemente, las actuaciones o manifestaciones que puedan derivarse de una norma de este tipo son casi infinitas, pero igual de evidente resulta reconocer que ni todas las actuaciones van a gozar de la misma protección, ni todas ellas van a tener la misma trascendencia; al menos desde el punto de vista jurídico. En las siguientes páginas analizaré más pormenorizadamente la relación existente entre la libertad regulada y el derecho subjetivo, y trataré de aclarar qué protección debe darse a las distintas manifestaciones que se derivan de la libertad.

\section{La libertad regulada y su conexión con el derecho subjetivo}

Tanto en la libertad regulada, como en el derecho subjetivo, se entabla una relación al menos entre dos partes: el titular de la libertad (o el derecho) y el destinatario de la misma. Si afirmamos que el destinatario es distinto del titular y que el titular tiene un derecho frente al destinatario, llegamos a la conclusión de que el destinatario tiene una obligación para con el titular ${ }^{34}$. Esta relación existente entre derecho y deber ha dado lugar a lo que se denomina teoría de la correlatividad, siendo numerosos los autores que se refieren a la inexcusable relación entre ambos conceptos. "Existe un poder del titular del derecho y un deber del titular de la obligación(...) El derecho y la obligación son correlativos y el uno no puede subsistir con independencia del otro"35. "El derecho/poder y el deber/obligación expresan una única situación, aunque desde dos perspectivas distintas. Son fórmulas intercambiables"36. "El concepto de deber suele ser contrastado con el de derecho(...) El derecho subjetivo de una persona presupone el deber jurídico de otra" ${ }^{37}$. Como vemos Kelsen también se refiere al concepto de deber jurídico, aunque dice que este solo puede ser entendido como tal si su no cumplimiento está respaldado por una sanción. Por su parte Hart considera que el fundamento

\footnotetext{
la resistencia que se oponga a la decisión de morir, en definitiva, “...la decisión de arrostrar la propia muerte no es un dere cho, sino simplemente manifestación de la libertad genérica..."

${ }^{34}$ Debo aclarar, con respecto a los conceptos de deber y obligación, que aunque los utilizo de forma prácticamente sinónima, no son exactamente lo mismo, de hecho en la doctrina encontramos diversas opiniones al respecto. Por ejemplo, García de Enterría y Tomás-Ramón Fernández distinguen entre deber en sentido amplio, que se impone en atención a intereses ajenos o de la colectividad, y dentro de esa categoría hablan de deber en sentido estricto, frente al que existe una potes tad, y obligación, frente a la que se sitúa un derecho subjetivo, en García de Enterría y Fernández (2020), pp. 31 y ss. Otros autores consideran que el deber suele entenderse en sentido moral y la obligación en sentido jurídico, es el caso de De Asis Roig (1991). Díaz Revorio se acerca a la primera de las opiniones ya que distingue entre deber en sentido amplio (que no lleva aparejado de manera inmediata una respuesta jurídica para el caso de incumplimiento y se entiende dirigido a los poderes públicos) y deber en sentido estricto y obligación, que sí contemplan la mencionada respuesta jurídica y se dirigen a sujetos vinculados, si bien el deber deriva de una norma y atiende a intereses generales y la obligación deriva de una relación jurídica y atiende a intereses particulares. Díaz (2011). ${ }^{35}$ Lumia (1993), p. 101.

${ }^{36}$ Díez-Picazo y Ponce de León (1999), p. 69.

${ }^{37}$ Kelsen (2010), p. 87.
} 
de la obligación jurídica está en la existencia de reglas sociales que son las que sirven como modelo para todas las actuaciones ${ }^{38}$.

Para Alexy, los derechos subjetivos deben entenderse como posiciones jurídicas que pueden ser de tres tipos: los derechos a algo, las libertades y las competencias ${ }^{39}$. Cuando se refiere a los derechos a algo, nos habla de relación triádica en la que interviene el titular, el destinatario y el objeto del derecho ${ }^{40}$. Considero que la relación triádica a la que se refiere el autor se va a dar tanto en la libertad regulada como en el derecho subjetivo, ya que el titular será el que podrá ejercer esa libertad o ese derecho, y el destinatario será un tercero o el Estado. Sin embargo, como veremos, la diferencia es que cuando estamos ante una libertad regulada, el deber de los demás consiste simplemente en no obstaculizar, mientras que el derecho subjetivo puede implicar otras obligaciones, dependiendo de las facultades que el derecho otorgue al titular.

La libertad regulada otorga a su titular un ámbito de libre actuación que es exclusivo para él y excluyente para los demás. Esto significa que ese ámbito sirve de límite tanto para el individuo como para terceros, ya sean particulares o el propio Estado. También permite al titular actuar libremente dentro de ese ámbito y exigir a terceros, ya sean particulares o Estado, la no obstaculización o interferencia en el mismo. Podemos decir que la libertad regulada otorga un derecho a omisiones. Digo que es un derecho a omisiones pues el deber u obligación del destinatario es omitir cualquier tipo de actuación que pueda estorbar al titular del derecho en el ejercicio del mismo. Es lo que Alexy denomina derechos de defensa o derecho a una acción negativa ${ }^{41}$.

En cuanto al derecho subjetivo, la doctrina ha aportado numerosas definiciones al respecto. Hago referencia a una de las que considero más adecuada para lo que trato de explicar, "el derecho subjetivo puede definirse como un poder o facultad del individuo que le atribuye un ámbito de libre actuación en relación con determinados bienes y la posibilidad de imponer un determinado comportamiento a otras personas, así como reclamar la defensa del interés protegido" 42 . De esta definición podemos deducir que el derecho subjetivo también comprende el derecho a omisiones al que me refería antes; no podemos olvidar que en esencia es una libertad. Algunos ejemplos serian la inviolabilidad del domicilio o el derecho a la propiedad

\footnotetext{
${ }^{38}$ Hart (1980), pp. 106 y ss.

${ }^{39}$ Alexy (2017), pp. 163 y ss.

${ }^{40}$ Alexy (2017), pp. 163 y ss.

${ }^{41}$ Alexy (2017), pp. 165 y ss.

42 Definición elaborada por Diez-Picazo y Ponce de León (1995), p. 2146.
} 
privada. En ambos se exige al destinatario una omisión o acción negativa: que no entre en el domicilio del titular o que no se haga aquello que pueda perjudicar su posición de propietario 43 .

Pero además, cuando estamos antes un derecho subjetivo, también se tiene "la posibilidad de imponer a un tercero el comportamiento elegido", lo cual no solo implica la no obstaculización por parte del tercero, sino la posibilidad de imponer esa decisión tanto al particular como al Estado, es decir, el derecho subjetivo también incluye lo que podemos denominar derecho a acciones. El titular del derecho está facultado para exigir al tercero una determinada conducta para que el ejercicio del derecho llegue a ser efectivo. Digo que es un derecho a acciones porque en este caso el deber del destinatario es siempre un hacer. Es lo que Alexy denomina derecho a una acción positiva ${ }^{44}$. Kelsen dice que

la conducta a la que un individuo está obliga do frente a otro, puede ser una conducta positiva o negativa, es decir, puede ser una acción o una omisión. La acción consiste en una prestación que el individuo obligado cumple con respecto de otro individuo. El objeto de la prestación es una cosa determinada o un servicio determinado (prestación de hacer o prestación de no hacer). La omisión a que un individuo está obligado frente a otro puede consistir en la omisión de determinada acción del propio individuo obligado, puede consistir en la omisión de impedir determinada conducta del otro individuo o de intervenir de algún modo en ella ${ }^{45}$.

Un ejemplo podría ser el derecho a la educación, cuyo destinatario sería el Estado, el cual tendrá la obligación de crear centros docentes para que pueda hacerse efectivo el derecho. Pero el destinatario también puede ser un particular, sobre todo si nos encontramos en el ámbito del derecho privado, pensemos, por ejemplo, en las obligaciones del deudor con respecto a los derechos del acreedor.

Desde mi punto de vista la diferencia cualitativa entre la libertad regulada y el derecho subjetivo está en que mientras en la libertad es suficiente la no interferencia por parte de terceros y del Estado, es decir, no se les puede exigir más que una actitud pasiva, en el caso del derecho podrá exigirse al Estado una posición activa, bien mediante medidas o normas que fomenten o incentiven ese derecho, bien a través de auténticas prestaciones que permitan hacerlo efectivo.

En ambos casos, tanto para la libertad regulada como para el derecho subjetivo, también comprenderían un derecho a tutela. Es la posibilidad que tiene el titular del derecho de recabar,

\footnotetext{
${ }^{43}$ Alexy diferencia tres tipos de derechos cuando se refiere a los derechos a acciones negativas, los derechos al no impedimento de acciones, derecho a la no afectación de propiedades o situaciones y derecho a la no eliminación de posiciones jurídicas. Alexy (2017), pp. 166 y ss.

${ }^{44}$ Alexy (2017), pp. 171 y ss.

${ }^{45}$ Kelsen (2010), p. 139.
} 
de los juzgados y tribunales, la protección necesaria ante posibles vulneraciones. Como dice Zagrebelsky, cuando se refiere a los derechos en su vertiente subjetiva, "son instrumentos para la realización de intereses individuales, confiados a la autónoma valoración de sus titulares, y además su violación autoriza a estos últimos a procurar su tutela (en las diversas formas posibles; autotutela, recurso judicial o resistencia)" 46 .

Este derecho que he denominado de tutela es lo que Ferrajoli denomina garantía secundaria, mientras que lo que el autor denomina garantía primaria se correspondería con los que he denominado derechos de omisiones y acciones.

Los derechos fundamentales, de la misma manera que los demás derechos, consisten en expectativas negativas y positivas a las que corresponden obligaciones (de prestación) o prohibiciones (de lesión). Convengo en llamar garantías primarias a estas obligaciones y a estas prohibiciones, y garantías secundarias a las obligaciones de reparar o sancionar judicialmente las lesiones de los derechos, es decir, las violaciones de sus garantías primarias $^{47}$.

Generalmente, el Estado frente a una libertad regulada tiene una actitud de indiferencia, pero respetando la decisión adoptada por su titular, es decir, lo normal es que el Estado simplemente se limite a no obstaculizar. Sin embargo, dependiendo del tipo concreto de libertad, puede incentivarla o desincentivarla. Por ejemplo, puede fomentar que los ciudadanos tengan hábitos alimenticios saludables, o desincentivar, cuando se trata de decisiones encaminadas a terminar con la propia vida; parece coherente que el Estado trate de desincentivar conductas suicidas o encaminadas a que la persona acabe con su vida.

También es posible que puedan darse libertades reguladas concretas, ante las cuales no es suficiente con que el Estado desincentive y tenga una actitud pasiva no obstaculizando, sino que pueden existir razones que justificarían una actitud activa por parte del Estado, pensemos, por ejemplo, en una huelga de hambre.

Lo que sí parece claro es que la actitud del Estado con respecto a una libertad regulada no incluye prestaciones de ningún tipo.

En cuanto al derecho subjetivo entiendo que puede suponer para el Estado un fomento o incentivación y/o prestaciones, dependiendo del tipo concreto de derecho.

\footnotetext{
${ }^{46}$ Zagrebelsky (2011), p. 85.

${ }^{47}$ Ferrajoli (2013), p. 26.
} 


\section{Las manifestaciones que se derivan de la libertad y su protección constitucional}

A pesar de la multitud de actuaciones que un individuo puede decidir hacer o no hacer, y que en cualquier caso están amparadas por la Constitución al existir una norma general de libertad, considero que puede hablarse de tres tipos de manifestaciones en cuanto a protección se refiere ${ }^{48}$.

1. Las que derivan de un derecho fundamental expresamente previsto en el texto constitucional.

2. Las que no derivan de los derechos expresamente previstos como tales, pero que pueden considerarse derechos subjetivos.

3. Las que no derivan de los derechos expresamente previstos como tales, pero que pueden considerarse libertades reguladas.

El primer tipo estaría formado por aquellas manifestaciones que claramente forman parte o se integran en un derecho fundamental. La manifestación gozará de las mismas garantías que el derecho.

El segundo y tercer tipo estaría formado por aquellas manifestaciones que claramente forman parte de nuestro agere licere, pero que difícilmente se encuadran en alguno de los derechos expresamente previstos en el texto constitucional. En estos casos, puesto que no nos encontramos ante derechos de los previstos por la Constitución, lo más interesante será determinar la protección que se les otorga a estas manifestaciones, pues en algunos casos podrán considerarse derechos subjetivos y en otros solo libertades reguladas.

Por lo pronto, al tratarse de libertades reguladas (pues hemos llegado a la conclusión de que todas lo son), otorgan a su titular lo que hemos denominado derecho a omisiones, sin embargo, no todas ellas podrán considerarse derechos subjetivos en el sentido de otorgar a su titular también un derecho a acciones.

\footnotetext{
${ }^{48}$ En España podríamos decir que existe un cuarto tipo: las manifestaciones que se derivan de un derecho constitucional (derecho previsto en la CE) pero que no se considerada fundamental. En la doctrina existe una polémica en cuanto a determinar qué dere chos deben considerarse fundamentales, y qué derechos son meramente constitucionales. Si bien no creo que sea necesario incidir en la misma, simplemente aclarar que todos ellos están reconocidos en la CE, sin embargo, un grupo de derechos, concretamente los reconocidos en los arts.15-29, gozan de las máximas garantías que la CE ofrece, mientras el resto solo goza de parte de las mismas.
} 
Ya me referí en un momento anterior al Tribunal Constitucional Federal alemán y el reconocimiento que se hace del derecho general de libertad. Alexy analiza esta jurisprudencia y explica de una forma clara qué supone el reconocimiento de este derecho, “...a cada cual le está permitido prima facie(...) hacer y omitir lo que quiera...” y “...cada cual tiene prima facie(...) un derecho frente al Estado a que éste no impida sus acciones y omisiones...", en definitiva, se le considera un derecho subjetivo, que no solo protege acciones, sino que puede proteger situaciones y posiciones jurídicas ${ }^{49}$.

Si nos centramos en el ordenamiento jurídico español, entiendo que no todas las manifestaciones de la norma general de libertad pueden considerarse derechos subjetivos, pues ello supondría, no solo que me otorgarían la posibilidad de decidir libremente qué hacer o qué no hacer, también implicarían un derecho a omisiones y un derecho a acciones en los términos referidos anteriormente. Personalmente, considero que no todas las manifestaciones que se derivan de nuestro agere licere pueden ser entendidas como derecho subjetivo, precisamente, porque no todas ellas facultan para exigir una acción o actitud activa por parte del destinatario de la misma. El derecho a acciones es, por tanto, el elemento clave para entender que ciertas actuaciones no pueden ser derecho subjetivo, sino solo libertades reguladas, que implican un ámbito de libre actuación y el poder exigir a terceros que no interfieran en el mismo.

También es importante recordar algunas ideas expuestas en páginas anteriores. Afirmar que existe una norma general de libertad supone reconocer que cualquier manifestación de esa norma, con independencia de que sea derecho fundamental, derecho subjetivo o libertad regulada tiene, al menos, rango constitucional, esto significa que, aunque puedan existir límites a dichas actuaciones, no pueden imponerse sin más, sin ningún tipo de justificación, pues un límite que no esté debidamente argumentado deberá ser tachado de inconstitucional, pues restringe una libertad de máximo rango.

\section{La disposición de la propia vida como libertad regulada}

Parece claro que la disposición de la propia vida es una manifestación de nuestra libertad. La misma no aparece de manera expresa en ningún texto constitucional. Tampoco encontramos supuestos en los que dicha manifestación se haya entendido como consecuencia directa de un derecho fundamental, expresamente previsto. Lo que suele ocurrir es que aquellos lugares en

${ }^{49}$ Alexy (2017), pp. 301 y ss. 
los que se permite poder disponer de la propia vida, se entiende que la misma es una decisión vinculada a la protección de diversos valores como la libertad, la dignidad o el libre desarrollo de la personalidad. Por tanto, lo habitual es que la disposición de la propia vida sea entendida como una manifestación de esos otros valores, la cuestión está en determinar si nos encontramos ante una libertad regulada o ante un derecho subjetivo.

Considero que la decisión de disponer de la propia vida es una libertad regulada que encontraría cobertura en la existencia de la norma general de libertad a la que me refería anteriormente. El hecho de ser una decisión que está dentro de mi ámbito de libertad me otorga, únicamente, un derecho a omisiones, es decir, puedo exigir a los terceros que no obstaculicen mi decisión de morir. Evidentemente, tal consideración implica una serie de consecuencias jurídicas de gran calado, y que a su vez pone sobre la mesa numerosas preguntas, ¿cuál debe ser la postura del tercero ante una decisión de suicidio?, ¿qué ocurre con la persona que quiere morir pero no puede quitarse la vida por ella misma?, ¿podríamos recabar la tutela ante la interferencia de un tercero? Sin duda se trata de interrogantes de gran interés, sin bien no pueden ser resueltos en este momento 50 .

Pero, la decisión de terminar con la propia vida, ¿podría entenderse como algo más? ¿podría ser un derecho subjetivo? Tal consideración no solo supone un derecho a omisiones, como en el caso de la libertad regulada, también supondría un derecho a acciones. Considerar la decisión de morir como derecho subjetivo permitiría al titular del derecho a la vida poder imponer a terceros su decisión, e incluso solicitar ayuda para llevar a cabo tal decisión si no pudiera hacerlo por si mismo. El tercero podría ser un particular o podría ser el Estado, en cuyo caso debería adoptar las medidas oportunas para que el que así lo decide pueda quitarse la vida.

Para contestar adecuadamente a estas preguntas habría que tener en cuenta otro aspecto importante: la teoría de la doble vertiente de los derechos formulada por el jurista alemán Konrad Hesse. La misma ha sido acogida por la mayor parte de la doctrina y por gran parte de los tribunales, por ejemplo, el TC ${ }^{51}$. Según esta teoría, todos los derechos tienen una doble vertiente: la objetiva o axiológica, que define la estructura política y social de un Estado, y la subjetiva, que otorga a su titular un status jurídico o libertad dentro de un ámbito de actuación,

${ }^{50}$ Puede consultarse Molero (2014) pp. 189 y ss.

${ }^{51}$ Lo hace desde una de sus primeras sentencias STC 25/1981, de 14 de julio. 
exclusivo para él y excluyente para los demás, status que puede imponer a terceros y hacerlo exigible.

Si asumimos que la dimensión objetiva de un derecho es la que define la estructura política y jurídica de un Estado, ello supone que él mismo está obligado a tutelar los derechos, protegiéndolos de los atentados que puedan sufrir por parte de terceras personas y adoptando las medidas necesarias para que puedan ejercerse con plena efectividad.

La dimensión objetiva del derecho fundamental(...) lo convierte en lo que ya hemos calificado como un mandato de optimización(...) comportan un determinado contenido normativo que debe ser realizado por los poderes públicos(...). El mandato impone que todo poder público tiene el deber positivo de proteger los derechos fundamentales(...) y le obliga a abstenerse de realizar cualquier acto que pueda resultar contrario al citado deber positivo... 52 .

Así las cosas, el derecho a la vida, como cualquier otro derecho, consta de ambas vertientes, y la vertiente objetiva del mismo obliga al Estado a proteger la vida allí donde se encuentre. Ello supone que no podré exigirle actitudes que fomenten o incentiven, y mucho menos que me otorguen, las medidas necesarias para hacer efectiva mi decisión de morir. Estas afirmaciones afectan directamente al derecho a acciones que forma parte del derecho subjetivo, impidiendo que tal consideración pueda ser aplicada para la disposición de la propia vida, que solamente podrá ser entendida como una libertad regulada, comprendida por un derecho a tutela y un derecho a omisiones.

Lo dicho de la vertiente objetiva debe unirse a otro aspecto importante: el hecho de que en el caso del derecho a la vida no pueden separarse titularidad y ejercicio. Cuando se trata de cualquier otro derecho, y gracias a su vertiente objetiva, el Estado también actúa como garante del mismo, sin embargo, al poder separase ambas realidades, el Estado velará por proteger la titularidad del mismo, si bien el ejercicio puede ser modulado por su propio titular, e incluso renunciando al mismo de manera temporal. Evidentemente, esto no es posible en el caso del derecho a la vida.

Personalmente, entiendo que la consideración adecuada de la disposición de la propia vida es como libertad regulada, no como derecho subjetivo, pues considero que no incluye la posibilidad de acudir al Estado para me ayude a morir. Dicha exigencia chocaría con su obligación genérica de proteger la vida allí donde se encuentre.

${ }^{52}$ Cita de Presno Linera recogida en Bastida (2004), pp. 50 y ss. 
Ahora bien, la consideración como libertad regulada es suficiente para aquellas personas que no quieren seguir viviendo y pueden acabar con su vida por ellas mismas, sin embargo, para aquellas otras impedidas de hacerlo, dicha libertad carece de efectividad. Si acudir al Estado no es posible, por la vertiente objetiva a la que me refería antes, considero que la opción jurídicamente adecuada es permitir que la persona que así lo solicita sea ayudada por un tercero particular; y que el mismo no sea castigado por ello.

\section{LO 3/2021, de 24 de marzo de regulación de la eutanasia}

Así las cosas, se acaba de publicar en España la última de las regulaciones mundiales en cuanto a disposición de la propia vida.

Dicha ley se refiere únicamente a la entendida como eutanasia activa directa, contemplándose dos posibles formas de llevarse a cabo: la acción directa realizada por un profesional sanitario, o la actuación que realiza la propia persona apoyada por un profesional sanitario, que será el que facilite los medios para hacerlo. Por tanto, se prevé tanto la eutanasia activa como la cooperación al suicidio.

Podrán recibir la prestación de ayuda para morir, como dice expresamente la ley, aquellas personas que sufran una enfermedad grave e incurable, y aquellas otras que tengan un padecimiento grave, crónico e imposibilitante. Entiende el legislador que nos encontramos ante un conflicto de derechos, y que ante una de las situaciones descritas anteriormente, el derecho a la vida puede ceder en favor de otros bienes igualmente protegibles, tales como la dignidad, la libertad y la autonomía de la voluntad.

Los requisitos que establece la ley para solicitar la prestación son los habitualmente exigidos en regulaciones similares a esta: mayoría de edad, plena competencia y que la petición se realice de manera libre, voluntaria, clara y reiterada (la norma requiere dos solicitudes con 15 días de diferencia la una de la otra). Cabe destacar que solo se prevé para españoles, o personas residentes legalmente en España con un tiempo de permanencia superior a 12 meses. La petición se podrá revocar en cualquier momento, y también se prevé el aplazamiento de la actuación. 
Asimismo, se reconoce la validez de lo estipulado en un documento de instrucciones previas o testamento vital, de tal forma que si al momento de realizar la solicitud la persona ya no es competente, se podrá tener en cuenta los previsto al respecto en dicho documento ${ }^{53}$.

La solicitud será valorada por triplicado: por un primer médico que será el responsable, por un segundo médico que será el consultor y finalmente, por la Comisión de Garantía y Evaluación (cuya composición será multidisciplinar), que emitirá el informe final, pudiéndose llegar al contencioso-administrativo si no fuese favorable a la petición.

También es importante resaltar que se prevé la objeción de conciencia para los profesionales sanitarios.

Para terminar con este sucinto repaso a la reciente ley española, quisiera referirme a algo que entiendo es crucial, y que trataré de hilar con las conclusiones de este trabajo. Dice el legislador español que el tratamiento que se le da a este tema en otros ordenamientos jurídicos gira en torno a dos posibles interpretaciones: despenalizar ciertas conductas eutanásicas, que se realizan por compasión y a petición del sujeto, y considerar la eutanasia como una práctica legalmente aceptable, siempre sujeta a requisitos y garantías. La regulación española sigue la segunda de las interpretaciones, argumentando, entre otras cosas, que esta es la posición que adopta el Tribunal Europeo de Derechos Humanos (TEDH) en lo que respecta al análisis de estas dos alternativas jurídicas ${ }^{54}$. En suma, el legislador español ha regulado la eutanasia como un derecho y lo ha incluido, como un servicio más, en el sistema público de salud.

\section{Conclusiones}

Cuando alguien decide disponer de su vida parece claro que está ejerciendo una libertad, lo que no resulta tan claro es determinar si esa libertad está amparada por el ordenamiento jurídico, y qué facultades concretas supondría tal protección. Las diferentes posturas que puedan tenerse al respecto no van a provocar las mismas consecuencias jurídicas, es evidente que no es lo mismo hablar de libertad como una mera alternativa de acción, que hablar de un

\footnotetext{
${ }^{53}$ Sin duda un tema muy interesante, y con una importancia creciente, es el de estos tipos de documentos. Una de las obras más completas al respecto es De Montalvo (2009).

${ }^{54}$ Se trata de la sentencia TEDH 14 de mayo de 2013 (caso Gross vs. Suiza), si bien sorprende la alusión a la misma, ya que su interpretación fue posteriormente rebatida por la Gran Sala.
} 
derecho que otorga a su titular una serie de facultades, que puede imponer a otros e incluso recabar su cumplimiento.

Como he tratado de explicar a lo largo de este trabajo, de las diversas manifestaciones que se derivan de la libertad, entiendo que la de disponer de la propia vida no se deriva de un derecho fundamental expresamente previsto como tal, por lo que su única configuración posible es como derecho subjetivo o como libertad regulada.

A mi juicio nos encontramos ante una libertad regulada, pues al reconocerse la existencia de una norma general de libertad todas lo son. Dicha libertad regulada otorga un ámbito de libre actuación exclusivo para el titular y excluyente para los demás. Esto significa que no solo podemos movernos de forma libre dentro de ese ámbito que la norma le concede, sino que además no podremos sufrir interferencias por parte de terceros que puedan obstaculizar nuestra actuación. Esta posibilidad es la que he denominado derecho a omisiones, esto es, el poder exigir a terceros (particulares o Estado) que no interfieren en la decisión. También incluye un derecho a tutela, en el sentido de poder reclamar que se respete el derecho a omisiones en caso de incumplimiento.

La libertad regulada se puede configurar como derecho subjetivo, cuando el titular de la misma también cuenta con un derecho a acciones, que consiste en la posibilidad de exigir al tercero determinadas actuaciones para poder hacer efectivo lo que el derecho establece.

En mi opinión, cuando hablamos de disposición de la propia vida no podemos hablar de derecho subjetivo, pues tal decisión no incluye el citado derecho a acciones, pues no podemos exigir al Estado una actitud positiva que me ayude en mi decisión de morir. Tal exigencia chocaría irremediablemente con la dimensión objetiva del derecho a la vida, o lo que es lo mismo, con la obligación que tiene el Estado de proteger el derecho allí donde se encuentre.

Aunque no es el objetivo de este trabajo realizar un análisis exhaustivo de la reciente regulación española, sí creo importante realizar algunas aportaciones a modo de conclusión.

Jurisprudencialmente, ya hemos visto que el TC considera que el derecho a la vida solo incluye la vertiente positiva, por lo que no quedaría reconocido el derecho a la muerte. Sin embargo, dicha interpretación ya queda lejana en el tiempo, además, muy posiblemente, la reciente ley será recurrida y nuevamente tendrá que pronunciarse el TC al respecto, ofreciéndonos, al menos, una argumentación más actual. 
Más allá de la interpretación constitucional, cabe decir que la regulación española sí permite que se proporcione ayuda para morir; siempre que se cumplan con los requisitos que la normativa establece.

Se refiere la ley a dos interpretaciones posibles: despenalizar ciertas conductas eutanásicas, que se realizan por compasión y a petición del sujeto, y considerar la eutanasia como una práctica legalmente aceptable, siempre sujeta a requisitos y garantías. La primera de ellas parte de la prohibición, y solo se permite en ciertos casos, la segunda parte del permiso, si bien puede prohibirse en ciertos supuestos; o si no se observan los requisitos exigidos. El legislador español opta por la segunda de las opciones y en virtud de la misma entiende que la eutanasia es un derecho, y por tanto la ayuda la prestaría el estado como un servicio más dentro del sistema público de salud.

Personalmente considero que, si asumimos la existencia de una norma general de libertad, la opción más adecuada es la seguida por el legislador si bien con un gran matiz, la práctica legalmente aceptable a la que se refiere la norma no puede entenderse como un derecho, pues ello chocaría con la vertiente objetiva del derecho a la vida, y la obligación que tiene el Estado de protegerlo, sino como una libertad constitucional legislativamente limitable 55 . Dicha libertad permitiría que un tercero particular pueda ayudar a morir al que lo solicita, sin que pueda ser castigado por ello.

Termino este trabajo aludiendo a otro aspecto que entiendo no se aborda correctamente en la ley. Se habla en diversas ocasiones, a lo largo del texto, de los valores implicados en el tema, afirmado expresamente que el derecho a la vida debe ponderarse y que en ocasiones debe ceder para proteger otros intereses. Se refiere la ley de manera explícita al valor superior de la libertad, a la autonomía de la voluntad, a la libertad ideológica y de conciencia, a la libertad de decisión, etc. Sin embargo, a pesar de este reconocimiento, la ley exige que exista una enfermedad grave, a la que debe acompañar otros elementos (crónica, incurable...) para que la petición sea atendida. Pero, qué ocurre si la enfermedad no es entendida médicamente como grave, pero a la

\footnotetext{
${ }^{55} \mathrm{~A}$ este respecto son interesantes las opiniones de Fernando Rey, quien aboga por entender la eutanasia como excepción permitida y Carmen Tomás-Valiente, quien considera que es más adecuado entenderla como libertad limitable. Rey (2008), pp. 87 y ss. TomásValiente (2003), pp. 65 y ss.
} 
persona le provoca un sufrimiento insoportable, e incluso, qué ocurre con determinadas situaciones que no provocan enfermedad, pero que para las personas que las sufren suponen una carga intolerable incluso imposibilitante para el desarrollo habitual y pleno de la vida; lo que en otros ordenamientos se ha llamado sufrimiento existencial. Me parece una regulación inadecuada e incoherente; si abrimos la libertad debemos entender que se abre para todo. Si hablamos en nombre de la libertad para dar luz verde a este tipo de actuaciones, debe serlo de igual forma para cualquier persona que así lo pida. No creo que el legislador tenga la capacidad para decidir qué padecimientos son merecedores de ayuda, en perjuicio de otros; máxime cuando se usa la libertad como sustento principal.

Definitivamente, los intereses y objetivos políticos no siempre coinciden ni van de la mano con los estrictamente jurídicos.

\section{Bibliografía citada}

A.A.V.V. (1995): Enciclopedia Jurídica Básica (Madrid, Cívitas).

Alexy, Robert (2017): Teoría de los derechos fundamentales (Traducc. Carlos Bernal Pulido, $2^{\underline{a}}$ ed. (Madrid, Centro de Estudios Constitucionales).

Bastida Freijedo, Francisco José y otros (2004): Teoría general de los derechos fundamentales en la Constitución española de 1978 (Madrid, Tecnos).

Berlin, Isaiah (2005): Dos conceptos de libertad y otros escritos (Traducc. Ángel Rivero, Madrid, Alianza Editorial).

De Asís Roig, Rafael (1991): Deberes y obligaciones en la Constitución (Madrid, Centro de Estudios Constitucionales).

De Montalvo Jääskeläinen, Francisco. (2009): Muerte digna y Constitución. Los límites del testamento vital (Madrid, Universidad Pontificia Comillas).

Díaz Revorio, Francisco Javier (2000): “Tribunal Constitucional y Derechos Constitucionales <no escritos>" en La Justicia Constitucional en el Estado Democrático (Valencia, Cortes de Castilla-La Mancha y Tirant Lo Blanch) pp.231-260. 
(2009): Los derechos humanos ante los nuevos avances Científicos y Tecnológicos. Genética e Internet ante la Constitución (Valencia, Tirant Lo Blanch).

(2011): "Derechos humanos y deberes fundamentales. Sobre el concepto de deber constitucional y los deberes en la Constitución Española de 1978", Revista IUS (Año 5, № 18) pp. 278-310.

(2018): Valores superiores e interpretación constitucional (Valencia, Tirant lo Blanch)

Díez-Picazo, Luis María, (2013): Sistema de derechos fundamentales (4⿳⺈⿴囗十$e d .$, Navarra, ThomsonCivitas).

Díez-Picazo y Ponce de León, Luis (1999): Experiencias Jurídicas y Teoría del Derecho (3ª ed., Barcelona, Ariel).

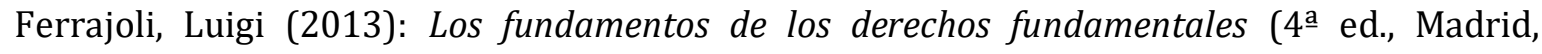
Editorial Trotta).

García de Enterría, Eduardo y Fernández Rodríguez, Tomás Ramón (2020): Curso de Derecho Administrativo II (16 ${ }^{\mathrm{a}}$ ed., Madrid, Thomson/Cívitas).

García Guerrero, José Luis (dir.) (2013): Los derechos fundamentales. La vida, la igualdad y los derechos de libertad (Valencia, Tirant Lo Blanch).

Gascón Abellán, Marina (1999): Obediencia al derecho y objeción de conciencia (Madrid, Centro de Estudios Constitucionales).

(2010): “Objeción de conciencia sanitaria” en Mendoza Buergo, Blanca (ed.), Autonomía personal y decisiones médicas. Cuestiones éticas y jurídicas (Madrid, Cívitas) pp. 143-162.

Hart, Herbert Lionel Adolphus (1980): El concepto de derecho (Traducc. Genaro Carrio, 2a ed., (México, Editorial Nacional).

Kelsen, Hans (2010): Teoría General del Derecho y del Estado (Traducc. Eduardo García Máynez, 3a ed. (México, Universidad Nacional Autónoma de México).

Lumia, Giuseppe (1993): Principios de teoría e ideología del derecho (Madrid, Editorial Debate). 
Molero Martín-Salas, Ma del Pilar (2014): La libertad de disponer de la propia vida desde la perspectiva constitucional (Madrid, Centro de Estudios Políticos y Constitucionales).

Pérez Royo, Javier (2018): Curso de Derecho Constitucional, 16a ed. (Madrid, Marcial Pons).

Prieto Sanchís, Luis (1990): Estudios sobre derechos fundamentales (Madrid, Debate). (2000): "La limitación de los derechos fundamentales y la norma de clausura del sistema de libertades" en Derecho y Libertades Revista del Instituto Bartolomé de las Casas (№ 8), pp. 429-468.

Rey Martínez, Fernando (2008): Eutanasia y derechos fundamentales (Madrid, Centro de Estudios Políticos y Constitucionales).

Rodotà, Stefano (2008): "Se la legge regola la vita e la morte", en La Repubblica, (18 de septiembre).

Romboli, Roberto (1994): La libertà di disporre del proprio Corpo (commentario del art. 5 del codice civile) (Bologna, Nicola Zanichelli Editore).

Tomás-Valiente Lanuza, Carmen (2003) "La disponibilidad de la propia vida: aspectos constitucionales" en Actas de las VIII Jornadas de la Asociación de Letrados del Tribunal Constitucional. El derecho a la vida (Madrid, Tribunal Constitucional y Centro de Estudios Políticos y Constitucionales).

Von Wright, Georg Henrik (1979): Norma y acción; una investigación lógica (Madrid, Tecnos).

Zagrebelsky, Gustavo (2011): El derecho dúctil. Ley, derechos, justicia, (Traducc. Marina Gascón, 10ª ed. (Madrid, Editorial Trotta y Consejería de Educación y Cultura de la Comunidad de Madrid).

\section{Normas jurídicas citadas}

Código Penal uruguayo № 9155, de 4 de diciembre de 1933.

Código Penal suizo de 3 de julio de 1938.

Constitución de la República italiana de 21 de diciembre de 1947. 
Ley Fundamental para la República Federal Alemana, de 23 de mayo de 1949.

Constitución española de 29 de diciembre de 1978.

Código Penal colombiano, de 20 de febrero de 1980 (no vigente en la actualidad).

Código Penal alemán de 13 de noviembre de 1988.

Ley Orgánica 10/1995, de 23 de noviembre, del Código Penal, en España.

Ley de Derechos de los enfermos terminales de 1 de julio de 1996 (Territorio del Norte de Australia. Actualmente derogada).

Ley de Muerte Digna de Oregón. (Aprobada por referéndum el 8 de noviembre de 1994, posteriormente queda unos años en suspenso, y vuelve a celebrarse un nuevo referéndum el 13 de mayo de 1997).

Ley de la Terminación de la vida a petición propia y del auxilio al suicidio de 1 de abril de 2002, de Holanda.

Ley sobre Eutanasia de 28 de mayo de 2002, de Bélgica.

Ley De Muerte Asistida de 31 de octubre de 2017. (№ 61 de 2017. Estado de Victoria, Australia. Entró en vigor en junio de 2019).

Ley De Muerte Asistida de 19 de diciembre de 2019. (№ 27 de 2019. Estado de Western. Entró en vigor en 2021).

Ley de Elección Final de la Vida, de 17 de octubre de 2020. (Nueva Zelanda, entrará en vigor el 6 de noviembre de 2021).

Ley Orgánica 3/2021, de 24 de marzo, de regulación de la eutanasia.

\section{Jurisprudencia citada}

Sentencia Tribunal Constitucional español: 25/1981, de 14 de julio.

Sentencia Tribunal Constitucional español: 83/1984, de 24 de julio. 
Sentencia Tribunal Constitucional español: 67/1985, de 24 de mayo.

Sentencia Tribunal Constitucional español: 89/1987, de 3 de junio.

Sentencia Tribunal Constitucional español: 161/1987, de 27 de octubre.

Sentencia Tribunal Constitucional español: 139/1989, de 20 de julio.

Sentencia Tribunal Constitucional español: 120/1990, de 27 de junio.

Sentencia Tribunal Supremo español: 10 de junio de 1994.

Sentencia Tribunal Constitucional español: 55/1996, de 28 de marzo.

Sentencia Tribunal Constitucional español: 136/1996, de 23 de julio.

Sentencia Tribunal Constitucional español: 153/1996, de 30 septiembre.

Sentencia Corte Constitucional de Colombia: 20 de mayo de 1997.

STEDH: 14 de mayo de 2013 (Caso Gross vs. Suiza).

Sentencia del Tribunal Constitucional alemán: 16 de enero de 1957.

Sentencia del Tribunal Constitucional alemán: 26 de febrero de 2020. 